\title{
LA ENSEÑANZA DE LA ORTOGRAFÍA EN COSTA RICA: DE LAS REGLAS FONODEPENDIENTES A LAS REGLAS RENTABLES Y AL PLANTEAMIENTO GRAFOLÓGICO
}

\author{
Carlos Sánchez Avendaño \\ Investigador del Instituto de Investigaciones Lingüísticas de la \\ Universidad de Costa Rica \\ San José, Costa Rica
}

Recibido 29-IV-2008 • Aceptado 13-V-2008 • Corregido 02-VI-2008

\begin{abstract}
Resumen: En este artículo, se aborda el análisis de los libros para la enseñanza de la ortografía en Costa Rica, el problema de las reglas ortográficas, el diagnóstico de las cacografías en la población estudiantil del país, las causas de las disortografías y algunos aspectos en torno a la enseñanza de este componente del registro escrito.
\end{abstract}

Palabras clave: Ortografía, problemas de ortografía, enseñanza de la ortografía, reglas ortográficas.

\begin{abstract}
In this article, some related subjects are analyzed: the textbooks for teaching spelling in Costa Rica, the problem of spelling rules, the diagnosis of spelling errors among the students, the causes of such errors and some aspects concerning how to teach spelling.
\end{abstract}

Key words: Spelling, spelling problems, spelling teaching, spelling rules.

\section{Introducción}

La ortografía es quizás el nivel más superficial en lo relativo al manejo del registro escrito; es decir, se trata de la representación gráfica convencional del discurso, sin relación evidente con su textualidad. Es cierto que las faltas ortográficas son, con toda probabilidad, lo primero que salta a la vista al observar un escrito y las causantes del estupor de quienes juzgan la calidad de la redacción de estudiantes y profesionales. No obstante, debe tenerse muy presente que una falta de ortografía difícilmente representa un problema real de cohesión, coherencia o, en general, de calidad en el contenido semántico-pragmático y su codificación gráfica.

Lo anterior parece difícil de aceptar o entender, pero debe ser el punto de partida: la ortografía, contrario a la puntuación -por mencionar únicamente otro recurso exclusivo del texto escrito-, no tiene que ver con la jerarquización de las ideas ni con su engarce. Constituye, sin más, un mero requisito impuesto sobre cómo representar el discurso en español, acerca del cual no 
cabe casi ningún criterio de decisión por parte del autor sobre la mejor manera de textualizar sus ideas.

Es tradicional, sin embargo, unir la enseñanza de la expresión escrita con el de la ortografía, hasta el punto de que muchos autores consideran que esta última es parte inseparable de la didáctica de la redacción (cfs. Sánchez, 2004a). Empero, como ya hemos tratado de mostrar en otro lugar (Sánchez, 2004b/2005), la expresión escrita guarda relación con la disposición de las ideas: la coherencia entre los contenidos de un texto, el mantenimiento de la identidad de los referentes de los cuales se habla, la informatividad de las porciones y rubros textuales, la conexión lógico-semántica y metatextual de las ideas, la segmentación y jerarquización de las unidades del discurso.

La ortografía, por su parte, no es tanto un asunto de expresión escrita como una mera representación gráfica; esto es, simple y llano acatamiento de una especie de dogma de la escritura. Por ello mismo, no coincidimos con afirmaciones como la siguiente: "El aspecto ortográfico es un elemento fundamental en la comunicación escrita, pues si el usuario de la lengua tiene un dominio de este rubro, su expresión va a mejorarse enormemente" (Bolaños, 1996, p. 329).

No obstante, negar la existencia del juicio social sobre las faltas de ortografía resultaría igualmente engañoso. Por consiguiente, en este artículo, echaremos un vistazo a la enseñanza de la ortografía en Costa Rica según se observa en los libros de texto que para ese propósito se han publicado y a las causas de las cacografías en la población estudiantil. Asimismo, se analizará el problema de las reglas ortográficas tradicionales y se mostrarán propuestas alternativas para la enseñanza de la escritura convencional. Por último, debe tenerse en cuenta que, para los efectos de este trabajo, empleamos con sinónimos los términos falta de ortografía, error ortográfico, disortografía y cacografía.

\section{Los libros para la enseñanza de la ortografía publicados en Costa Rica}

El primer texto para la didáctica de la escritura convencional que hallamos es la Ortografía de Gámez de $1928^{1}$, en el cual se practica la enseñanza a partir de reglas. En este autor, la recurrencia a cuestiones de pronunciación es patente; muchas son incluso falsas, como la afirmación de que "la $b$ se pronuncia juntando los labios y emitiendo el sonido; la $v$, el labio inferior con los dientes de arriba" (Gámez, 1928, p. 9); es decir, recomienda la diferenciación entre el sonido oclusivo bilabial y el fricativo labiodental, supuestamente representados por las letras $b$ y $v$, respectivamente, distinción desaparecida del español ya desde el siglo $\mathrm{XVI}^{2}$.

En su método, Gámez trata diferentes reglas relativas a cada una de las consonantes que alternan en la representación de un sonido, echando mano de metalenguaje gramatical e indicaciones etimológicas para que se comprenda el uso respectivo, como se puede apreciar en los siguientes ejemplos:

[se usa $v$ ] En el pretérito de indicativo, las dos formas pretéritas del subjuntivo y el futuro hipotético de estar, andar y tener y sus compuestos (Gámez, 1928, p. 38).

[se usa $h$ ] En las voces que en su origen tuvieron $f$ : harina, hermosa, hijo, habla, hacer etc. (Gámez, 1928, p. 60).

De los ejemplos anteriores se desprenden con facilidad dos conclusiones: para escribir con ortografía hay que conocer -y entender, claro está- el metalenguaje gramatical tradicional y, por si esto fuera poco, saber latín (además de griego clásico) y lingüística histórica del español, con el fin de saber cuáles palabras provienen de cuáles en latín o griego, cómo se escribían en tales lenguas y, por supuesto, qué modificaciones se produjeron en el proceso del cambio idiomático. Lo descabellado de tal 
requerimiento convierte la enseñanza a partir de reglas en una técnica sin éxito.

Siguiendo la línea de Gámez, es común hallar en la primera mitad del siglo $\mathrm{XX}$ textos breves en los que se desglosan y explican temas provenientes de los programas oficiales de educación. Se trata de libros que se ocupan de la enseñanza de la ortografía, pero como un componente más de la didáctica de la lengua y como guía para quien enseña. Un ejemplo es el libro de Sotela (1929), en el que, siguiendo la tónica expuesta, es constante la referencia a la pronunciación, la gramática tradicional y la historia de la lengua.

En nuestro medio, tan solo un año después, Zamora Elizondo va a replantear la cuestión y poner en duda la eficacia del método reseñado:

La ortografía (...) no puede ser otra cosa que el aprendizaje de un mecanismo que ha de convertirse, a fuerza de práctica, en un hábito. Buscar etimologías o recordar reglas ante cada palabra que se quiera escribir, será buena labor para el filólogo (...), pero resultará, para todos los hombres, labor algo menos que imposible de realizar perfectamente en el mecanismo corriente de la escritura (...) (Zamora, 1930, p. 4).

Para este autor, no solo la enseñanza a partir de reglas y etimologías resulta poco práctica, sino que también cuestiona la funcionalidad de la copia y del "dictado de fiscalización" (aquel sin explicación previa y en el que el profesor se dedica a señalar los errores de un escrito), para proponer que sólo el dictado con previo análisis ortográfico podría lograr algún éxito, siempre y cuando se trate de párrafos y no de palabras, pues este último material suele componerse de elementos rebuscados, sin relación ni utilidad para la vida del aprendiz.

En 1939, Moisés Vincenzi también pone en evidencia los errores de una enseñanza descontextualizada y condenada al fracaso, como ya lo señalamos con respecto a otros temas de la expresión escrita (cfs. Sánchez, 2004a/b), pero en este caso en lo relativo a la ortografía:
Los maestros de la escuela antigua pensaban que la enseñanza de las reglas ortográficas, sin la motivación vitalista correspondiente, era capaz de proporcionar resultados prácticos. Por esto creyeron que bastaba memorizarlas, en forma mecánica, para cumplir su propósito. Recordamos, por ejemplo, cómo se pretendía que en un cuarto grado aprendiéramos a escribir un grupo de palabras en que entraba en juego la letra V. Lo vamos a transcribir de memoria, pero con la confesión de que jamás hemos pensado en el curioso párrafo a que aludimos, en los momentos de escribir cualquiera de las palabras que lo integran. Helo aquí:

«Avezado, civil, revoloteo; cervuno, acervo, envío, cerviz, ovado; prevaricar, convexo, chichisveo; obvio, estavio, longevidad y ovillo; malévolo, avispado y revoltillo.»

Como se ve, no hay en este trozo ni dos palabras que los niños de cuarto grado conozcan. Es decir que no sólo es absurdo el fragmento, en sí mismo considerado: también por lo exótico de las voces que lo componen. Y además debe agregarse el ningún efecto provechoso que nos haya aportado en nuestra propia experiencia, no sólo de hombres corrientes, sino, además, en nuestra actividad de escritores.

El caso anterior es notable por el ridículo antipedagógico que supone; pero hay casos en que este ridículo ha victimado a generaciones enteras de estudiantes (Vincenzi, 1939, p. 7).

Si bien Vincenzi no se escapa de supravalorar el lugar de la ortografía al tildar las faltas como determinantes de un "grado inferior de cultura", se preocupa más por indicar que, en términos sociales, goza de prestigio el saber escribir convencionalmente las palabras y que ello se debe enfatizar en las clases con el fin de que el estudiantado comprenda la importancia de la ortografía. Luego, se debe trabajar la escritura partiendo del vocabulario y los conocimientos propios de la niñez con respecto a la escuela y el medio circundante, con lo cual se desechan las reglas ortográficas por ser un "aprendizaje muerto" y por su incapacidad de conducirnos al "círculo vital del niño".

Para ejemplificar lo anterior, Vincenzi se basa en un estudio sobre el léxico infantil costarricense realizado varios años antes ${ }^{3}$ y en uno propio sobre el vocabulario de los jóvenes de secundaria, con el propósito de elaborar las listas de las palabras más 
usuales para cada nivel de instrucción, pero enfatiza en la necesidad de adaptar y modificar tales listas dependiendo de cada cantón, para así sustituir las palabras que no se empleen en el lugar respectivo por las que sean de uso más frecuente.

A partir de este punto, se aprecia que la propuesta de Vincenzi representa un paréntesis en la práctica tradicional de la enseñanza de la ortografía, pues los autores posteriores a él continúan más bien por la vía de Gámez: todos concuerdan en presentar listados de reglas de difícil aplicación, con la pretensión de que, haciéndolo así, el estudiante mejorará su escritura: Moya (1981), Porras (1972), Soto et al. (1988), Garita y Quesada (1988) ${ }^{4}$, Pazos (1990), Varela y Sandino (1993), Bolaños (1996), Pacheco y Álvarez (1997), Fernández (2001).

Se suele también remitir a un criterio de relación entre la pronunciación y la grafía, como es lógico para una lengua cuyo sistema de escritura se concibe como representación de los sonidos o, mejor dicho -como se expondrá luego- de los fonemas. Por ello mismo, no es extraño que se comenten temas relativos a fonética y fonología, aunque, desafortunadamente, estos no suelen ser muy acertados. Así, por ejemplo, en Pacheco y Álvarez (1997, p. 221) encontramos la afirmación de que "las vocales son sonoras y pueden formar sílaba; no así las consonantes, las cuales necesitan de ellas para tener sonido", en la cual resulta totalmente falsa la consideración de que las consonantes no tienen sonido. Las alusiones a la fonética también suelen ser oscuras y nada esclarecedoras, como en este ejemplo de Porras (1972, p. 51): "Se usa $\mathrm{V}$ en todas las formas verbales derivadas de infinitivos que no tengan este sonido: detener, detuvo".

El problema de este criterio "oralista" para la enseñanza de la ortografía consiste, en el caso particular de las reglas que venimos comentando, en que muchas veces se abusa de la conexión sonido-letra, la cual no revela, en el sistema de escritura actual del español, una relación uno a uno $\mathrm{y}$ hace que los autores presenten reglas del siguiente tipo: "Se escriben con "h" las voces que comienzan con los sonidos hidr, hiper, hipo" (Soto et al., 1988, p. 177), en cuyo caso se aprecia el sinsentido de hablar de una secuencia de sonidos en la que, en apariencia, aparece $h$, aunque esta carezca precisamente de sonido; o el siguiente: "Se escribe con "z" la terminación "azo" de los aumentativos que poseen este sonido" (Soto et al., 1988, p. 132), regla esta última que no aclara cuál es el sonido representado por $z$ y que resulta tautológica y, peor aún, desprovista de todo sentido para un hablante hispanoamericano, en cuyo caso la letra $z$ representa el mismo sonido de $s$ e incluso de $c$ (antes de las vocales $e, i$ ).

\section{$2.1 \quad$ El problema de las reglas ortográficas}

Como se observa en el punto anterior, a juzgar por los libros de texto, la didáctica de la ortografía en nuestro país consiste en gran medida en la memorización de listas de reglas, pues se cree fielmente que estas son valiosas y funcionales para desarrollar una escritura convencional (en realidad, los autores hablan de "correcta"), aunque se reconozca la existencia de otros factores:

(...) a continuación se le ofrece una serie de reglas a las que se debe ajustar cada letra para su debido empleo.

Tener ortografía correcta es el resultado de un proceso mecánico que se da con la práctica y la experiencia; sin embargo, las reglas ortográficas son un gran apoyo para el mejoramiento de la escritura.

No obstante, es necesario leer mucho pues la memoria fotográfica ${ }^{5}$ también es determinante (Pazos, 1990, p. 43).

Partiendo de lo anterior, vale la pena examinar la construcción de tales reglas. En general, los listados de reglas tienen el mismo inconveniente que señalamos para la puntuación (Sánchez, 2004b): no es patente la relación entre una regla y otra, 
y aprenderlas de memoria representa una carga que, mientras no se ponga en práctica y se reconozca su valor, de nada sirve, con el problema añadido de que, en el caso de la ortografía, las reglas son poco funcionales.

A este respecto, resulta provechoso seguir a Swan (1994), quien, al tratar de discernir lo que caracteriza una buena regla pedagógica, propone seis criterios: verdad, demarcación, claridad, simplicidad, parsimonia conceptual y relevancia.

Una regla pedagógica debe retratar la verdad: es fundamental no caer en contradicciones o en falsos ejemplos cuando se da una regla, pues con ello en cierto modo estamos faltando a la verdad, como en el siguiente caso, en el cual se consignan tres ejemplos (sustantivos) que no pertenecen a la clase gramatical que se especifica en la regla (adjetivos); es decir, hay más ejemplos de elementos que no están incluidos en la regla que de los que sí lo están (se indican con subrayado los sustantivos):

[se usa $v$ en] La terminación -ivo, -iva en adjetivos calificativos: $\underline{\text { motivo }}$ - pasivo - oliva - deriva - vivo (Pazos 1990, p. 51).

La regla debe estar demarcada o delimitada, de forma tal que muestre con claridad cuáles son los límites en el uso de una forma: no sirve a menos que demarque claramente el área dentro de la cual una forma (la letra, en nuestro caso) resulta apropiada, para que un aprendiz sepa cuándo usarla y cuándo no. Las reglas ortográficas suelen ser deficientes en este último aspecto, pues sus límites rara vez son evidentes, como en "[se escriben con $b$ ] Las palabras que tienen las combinaciones BL, BR, MB” (Moya, 1981, p. 31), para cuya aplicación sería necesario saber cuáles palabras se escriben precisamente con tales combinaciones, en particular en el caso de $\mathrm{MB}^{6}$; de lo contrario, podría ser que se escriba "eMBidia".

Así, se podría afirmar que las reglas ortográficas son, en su mayoría, poco útiles por problemas de delimitación. Básicamente, se trata de reglas tautológicas: para saber que se escribe ' $m$ ' primero se tiene que saber que se escribe la palabra con 'b' y no con 'v', como en el caso de 'convicción' y 'convencer'. La regla de que se escribe 'b' después de 'm' es totalmente circular e inservible.

Las reglas también deben ser claras, fáciles de comprender. Muchas veces las reglas son poco claras debido al uso de una terminología muy especializada, como se observa en el siguiente caso, el cual resulta totalmente oscuro para quien desconozca el sentido del tecnicismo "primitivo" en gramática y -justo es decirlo- aun para quien sí lo conozca:

La terminación -SIDAD cuando proviene de un primitivo, se escribe con $\mathrm{S}$. En los demás casos, es con $\mathrm{C}$ (Moya, 1981, p. 50).

Una regla pedagógica debería asimismo ser simple, criterio que se refiere, sobre todo, a la manera en que se formula una explicación. La simplificación implica hacer las descripciones más manejables, reduciendo el número de categorías o subdivisiones o dejando por fuera los detalles no esenciales. Por ejemplo, para comprender la siguiente regla, poco ayuda que se categorice la y como conjunción copulativa; además, el desglose de subreglas torna oscura la regla principal:

La "y" se utiliza como conjunción copulativa, pero puede sustituirse por e cuando precede a palabras que comienzan por i o hi. No obstante, se mantiene la y en principio de interrogación o si la palabra siguiente empieza por hie (Soto et al., 1988, p. 155).

El criterio de parsimonia conceptual se refiere a la necesidad de que las explicaciones hagan uso del marco conceptual disponible para quien aprende. La simplicidad y la claridad no son suficientes; se puede reducir la complejidad de una explicación, emplear poca terminología, y aún así dejar algo que es difícil de abarcar para un no especialista. Por ejemplo, las reglas de acentuación escrita resultan difíciles en el tanto exigen, para su comprensión, que 
el estudiantado sea capaz de determinar conscientemente el acento de intensidad en la pronunciación (cfs. Pérez, 1991).

Por último, una regla debería responder una pregunta real o potencial y nada más que esa pregunta que se formula quien estudia ortografía, con lo cual se atendría al criterio de relevancia. De este modo, una regla que contenga más información de la necesaria para aclarar la escritura convencional de una palabra encuentra su falla en la irrelevancia de esa información adicional, como ocurre en el siguiente ejemplo, en el cual lo único que le interesa a quien escribe para fines prácticos es saber si las palabras sobreesdrújulas se tildan o no y dónde, no si existen primitivas, cuándo se forman o si los adverbios en -mente presentan dos acentos (en la pronunciación) o no:

No existen palabras primitivas sobreesdrújulas; éstas se forman cuando se les agregan pronombres enclíticos, a verbos conjugados o verboides. En ellas el acento aparece después de la antepenúltima sílaba.

perdiéndoseles convirtiéndoselos

ejecutándoseme partiéndosele

Es importante destacar que la terminación "mente" no convierte la palabra en sobreesdrújula; porque no cambia el acento, sino más bien adquiere otro acento; es decir, tendrá dos acentos.

útilmente- grave ortográfica

médicamente- esdrújula

(Pacheco y Álvarez, 1997, p. 227).

Como ha quedado en evidencia, las reglas ortográficas son altamente deficientes en su presentación, nada claras y tautológicas. Pero, como si esto fuera poco, son además poco rentables; es decir, no se pueden aplicar a muchos casos. A este respecto, Zamora (1942) arremete contra la enseñanza tradicional de la ortografía por medio de reglas y dictados, pues sostiene que tal método memorístico está errado al no abarcar a más del 10\% de las palabras del español y al presentar varias excepciones. Aún sabiendo etimología y gramática tradicional y siendo capaces de reconocer las palabras primitivas de las derivadas, no estamos exentos los escribientes de español de toparnos con que las reglas ortográficas siempre nos demandarán más y más resignación:

Los derivados de hueso, huérfano, huevo, hueco, no llevan $h$ : osamenta, osario, osambre, óseo; orfandad, orfelina, orfanato; ovario, oval, óvalo, ovalar, ovar, ovillo; oquedad (Gámez, 1928, p. 59).

\section{La causa de los problemas ortográficos: el desfase entre fonología y ortografía}

Chavarría (1988) sostiene que gran parte de los ejemplos de disortografías encuentran su razón de ser en el desfase actual de un sistema creado para representar unidades fónicas con respecto a los cambios de pronunciación que, como le sucede a toda lengua natural viva, se han suscitado. La ortografía del español es conservadora y anacrónica: representa distinciones fonéticas y fonológicas inexistentes en el habla actual.

Para comprender a cabalidad la posición de Chavarría, vale la pena dirigir la atención, al menos de paso, a algunos de los sistemas de escritura de las lenguas. El sistema de escritura del español es fonográfico: no se representan palabras ni unidades de significado, sino sonidos. Otros sistemas de escritura también fonográficos representan igualmente unidades mayores de pronunciación, como las sílabas (por ejemplo, el sistema hiragana del japonés). No ha de pensarse, sin embargo, que esas son las únicas posibilidades. Para el chino, por ejemplo, se desarrolló un sistema de escritura logográfico, en el cual no se emplean símbolos para representar sonidos, sino unidades de significado, lo cual, aunque tiene el inconveniente de requerir la memorización de miles y miles de símbolos diferentes, implica que no se produce un desfase entre la representación gráfica de 
una palabra y su respectiva pronunciación, pues en realidad, en principio, no guardan relación.

Es en este sentido en el que deben entenderse las afirmaciones de Chavarría:

la escritura fonológica del español contemporáneo, en ninguna de sus tantas variedades habladas, nos ofrece base alguna objetiva que justifique la distinción ortográfica entre b y v. Dicho de otro modo, hay razones históricas que explican la presencia de las grafías b y v en el español contemporáneo, pero esas razones no justifican esa distinción puramente ortográfica. Escribimos 'base' y no 'vase', 'vaca' y no 'baca' por la simple razón de que ambas palabras provienen de palabras latinas con $\mathbf{b} \mathbf{y} \mathbf{v}$ inicial, respectivamente: basis y vacca, y por ninguna otra razón” (Chavarría, 1988, p. 15; destacados en el original).

Este mismo autor asevera que las cualidades que hacen que un sistema ortográfico se pueda considerar aceptable son dos: 1) debe poder representar de forma económica, eficiente y sin lugar a ambigüedad el sistema lingüístico y 2) debe resultar sencillo de aprender para los propósitos utilitarios de escribir y leer textos.

Precisamente, la ortografía del español no respondería con real apego a estos dos principios. Por poner un caso, como lo expone con claridad Chavarría (1988), las mayúsculas son un anacronismo innecesario, pues no aportan nada, pero han llegado a identificarse tan fuertemente con la representación gráfica del español que supondría poco probable que se eliminaran. En todo caso, lo deseable sería que su empleo se atuviera a reglas simples y de fácil seguimiento, en lugar de ser poco económicas, ambiguas y difíciles de aprender.

Otro problema, el relativo a las consonantes, consiste en la existencia de varias letras para la representación de un mismo fonema, imperfección de nuestro sistema de escritura que lleva a los usuarios a cometer errores en su empleo. Precisamente, los hablantes comenten faltas de ortografía en los casos en los que existen alternantes gráficos para la representación de una misma unidad fonológica ${ }^{7}$ / /b/ representado con $b \sim v$ : barco, vaso; /s/ representado con $s \sim c \sim z$ (especialmente en el caso de Hispanoamérica): saco, cielo, zapato; /x/ representado con $g \sim j$ : gitano, jinete; h que no representa nada (usualmente empleada por tradición etimológica): hielo, anhelar; /j/ representado con $l l \sim y$ : llave, yegua; /n/ representado con $m \sim n$ (antes de otra consonante): ambos, antes; $/ \mathrm{k} /$ representado con $c \sim q u$ : cuero, queso; /r/ representado con $r \sim r r$ : ratón, carro, alrededor, enredo; /ks/ representado con $x \sim c c$ : conexión, acceso.

Además, debemos considerar la poca claridad y rentabilidad de las reglas ortográficas, como ya se detalló en el apartado anterior. Chavarría nos regala un ejemplo más que contundente:

En un libro que tengo por delante (...) se lee, entre otros tantos disparates, lo siguiente en la sección dedicada -iválgame Dios!- a 'La ortografía del fonema $/ \mathrm{h} /{ }^{\prime 8}$ (...): 'Se escriben con ' $h$ ' las voces que comienzan con los sonidos hidr, hiper, hipo'. Pero el premio del absurdo se lo merece esta observación: 'Se escriben con 'h' todas las formas de los verbos que la llevan en el infinitivo. Nótese que en ambos casos no hay más explicación, no hay referencia al habla; se apela a la memoria, y a falta de ella tiene uno que andar con el diccionario a cuestas. Y ¿cuáles, precisamente, son los verbos que llevan $\mathbf{h}$ en el infinitivo y cuáles no? ¿Cómo saberlo? Si se parte de la premisa que [a'yar] se escribe 'allar' (o 'ayar') y no 'hallar', ¿adónde nos lleva esa regla? Al mismo nivel de claridad y comprensión yo pondría la siguiente 'regla' tomada un tiempo atrás del suplemento 'educativo' de un periódico local: 'Se escriben con aje las palabras que terminan en aje menos ambages'. ¡Vaya! Esto está a la altura de definir el naranjo como el árbol que produce las naranjas y luego definir la naranja como el fruto del naranjo (Chavarría, 1988, p. 49-50).

Las causas lingüístico-didácticas de los problemas ortográficos serían, en consecuencia, básicamente dos, según lo reseñado: el desfase entre el sistema fonológico del español moderno y su representación gráfica (la conservación de reliquias gráficas como $v$ y el empleo de la misma letra para representar distintos fonemas o de varias letras para un solo fonema), y la 
poca claridad y rentabilidad de las reglas pedagógicas para su enseñanza.

\section{El diagnóstico de las cacografias}

La primera alusión a los problemas ortográficos del estudiantado en Costa Rica la encontramos en Bruck:

Poco después de haber llegado a Costa Rica, me di cuenta de que los trabajos escritos de los alumnos de Primera y Segunda Enseñanza contenían muchos errores ortográficos, de determinados tipos, que muy raras veces había encontrado en los trabajos de escolares y estudiantes españoles ${ }^{9}$ (Bruck 1942, p. 3).

Si bien el autor no aclara cuáles son con exactitud tales errores, en su método recoge palabras relativas a los pares o conjuntos de letras que hemos comentado con anterioridad con respecto a la representación gráfica de las unidades fonológicas.

Años más tarde, en su estudio de 1985, Rodino y Ross mencionan los problemas de ortografía encontrados por ellos en las redacciones de los estudiantes universitarios: confusiones de letras y falta de tildes. Para estos autores, el problema se debe a la transferencia de la pronunciación a la escritura; en otras palabras, los alumnos escriben tal como pronuncian, pues no conocen las reglas que rigen la representación gráfica del español: activida, fasina, chiniada, pasiar, optener, asoluta, satisfación, alunnos, aveces.

En Rojas et al. (1985) también se estudian los problemas de ortografía de los estudiantes de primaria y secundaria, mediante pruebas de ítemes de complete con las letras respectivas y en redacciones. Los resultados son calificados por las investigadoras como deficientes: el promedio por debajo del $60 \%$.

Chavarría (1988), mediante el análisis de letreros, periódicos, graffiti, ejemplos recogidos en sus cursos universitarios, composiciones y dictados recopilados de estudiantes de secundaria, se dedica no solo a sistematizar los errores más frecuentes, sino también a determinar la tendencia de sustitución; esto es, determinar cuál letra tiende a ser reemplazada por otras: $\mathbf{s}$ por c: $156, \mathbf{s}$ por $\mathbf{z}: 122$, c por $\mathbf{s}: 53, \mathbf{z}$ por $\mathbf{s}$ : 12 , b por v: $100, \mathbf{v}$ por b: $92, \mathbf{y}$ por ll: $10, \mathbf{l l}$ por $\mathbf{y}: 20$, $\mathbf{g}$ por $\mathbf{j}: 22$, $\mathbf{j}$ por $\mathbf{g}: 2$, a partir de lo cual concluye que la tendencia a sustituir s por c y z predomina sobre lo contrario.

En relación con la tilde, Chavarría califica esta como aquel elemento ortográfico con respecto al cual se cometen más errores: omisión general y en hiatos, omisión en su uso diacrítico (distinción léxica o funcional: él/el, qué/que) y aparición indebida. Su deficitario manejo lo achaca a lo siguiente:

Para tildar una palabra se tiene que interrumpir el fluir de la escritura, el progreso de la ortografía cursiva, y esto probablemente es lo que contribuye a la frecuente omisión de la tilde (como el punto de la i) (Chavarría, 1988, p. 73).

Más recientemente, Murillo (2003), con base en el estudio de un corpus representativo y un riguroso análisis estadístico, sistematiza los errores ortográficos del estudiantado de primaria de tres formas: un vocabulario cacográfico basado en el léxico básico, las formas verbales escritas con errores y las palabras con dificultad organizadas por reglas. Por ejemplo, encuentra que algunas de las palabras más frecuentes con dificultad ortográfica son haber, después, echar, empezar, oír, pelear y agarrar.

En nuestro corpus de redacciones de estudiantes universitarios (cfs. Sánchez, 2005), los problemas de confusión entre letras aparecen poco. A todas luces, la razón es que sus textos fueron escritos en computadora y, con toda probabilidad, activaron algún tipo de corrector ortográfico. Precisamente, los errores que encontramos son los que tales herramientas informáticas no suelen detectar con facilidad, aunque registramos, aún así, unos pocos casos 
de cacografías consonánticas: b por v: bagancia, grabes; v por b: desaprovación; $\mathbf{g}$ por gu: giarse; s por z: madures, comensado; s por c: sircunstancia, ensima; c por s: paices, repercucion; z por c: realizé; $\mathbf{z}$ por $\mathbf{s}$ : pobrez; $\mathbf{n}$ por $\mathbf{m}$ : inportar; ll por $\mathbf{y}$ : halla por haya; $\mathbf{j}$ por $\mathbf{g}$ : cirujía.

Con claridad, se nota que los problemas a este respecto son exactamente los mismos que ya han sido diagnosticados y que las causas aducidas por Chavarría (1988) se verifican una vez más. Empero, queremos llamar la atención sobre un factor no considerado.

Dado que las reglas ortográficas difícilmente son rentables y de fácil aplicación, es obvio que la ortografía se aprende merced a la memoria visual; es decir, es por medio de una lectura atenta, centrada en la forma y no solo en el significado, que las personas aprenden a escribir una palabra. La acción de esta memoria visual incide también en la escritura por analogía; esto es, la tendencia a escribir una palabra de determinada manera porque se parece a otra o porque tiene una terminación igual a otra, así que se le aplica la misma escritura. Creemos que esto es lo que sucede, por ejemplo, en los casos de c por $\mathbf{s}$ (paices, repercucion) y $\mathbf{z}$ por $\mathbf{c}$ (realizé). Por poner un caso, es una regla de aplicación frecuente que las palabras terminadas en $\mathbf{z}$ la cambien por $\mathbf{c}$ al agregársele la marca de plural -es: pez $>$ peces, ve $\underline{z}>$ veces; probablemente, entonces, el estudiante relaciona visualmente paíces con peces y veces, así que está sobregeneralizando una regla.

Como se ve, el fenómeno es más complejo de lo que se ha señalado, porque no se trata únicamente en un problema en las reglas y la enseñanza tradicional de la ortografía, o de desfase entre el sistema fonológico del español y su representación gráfica, o de inconsistencia en la representación y en las reglas, o, incluso, de transferencia de la oralidad a la escritura, sino también de generalizaciones por analogía que inciden en la forma en que se recuerda visualmente la ortografía de una palabra.

\section{La ortografía y su enseñanza: Más allá de las reglas tradicionales}

Es evidente que el sistema ortográfico actual del español no representa unívocamente cada una de las unidades fonológicas, como ya se ha comentado. Nos detendremos, brevemente, en algunas disquisiciones teóricas con el fin de aclarar ciertos conceptos fundamentales para comprender mejor la argumentación de Chavarría (1988) y la de quienes, como él, consideran que las cacografías deben su existencia, sobre todo, a la falta de correspondencia entre el sistema fonológico y el ortográfico del español.

En la teoría lingüística estructural, el fonema se define como una unidad sonora que cumple una función distintiva en la lengua. Por ejemplo, las palabras 'pato' y 'dato' se diferencian una de la otra únicamente por razón de la presencia de /p/ frente a /d/. Se diría, entonces, que $/ \mathrm{p} / \mathrm{y} / \mathrm{d} /$ cumplen una función distintiva y son, en consecuencia, fonemas distintos en español (y por ello se representan técnicamente entre barras oblicuas). Los sonidos, por su parte, son unidades de pronunciación, sobre las cuales no se considera su función, sino que simplemente se describen en términos de, por ejemplo, los mecanismos articulatorios de su producción. En resumen, un sonido es una unidad material, articulatoria y acústica, mientras que un fonema es una unidad abstracta, relacionada más con la función distintiva que permite distinguir entre unas palabras y otras.

Los fonemas o unidades fónicas funcionales suelen manifestarse en más de un sonido; por ende, se acostumbra hablar de que un fonema se realiza como una serie de variantes fónicas, conocidas como alófonos. Así, para ilustrar, el fonema/b/ del español posee, al menos, dos variantes de 
realización o alófonos: [b] y [B]. El primero de ellos se describe, en términos de fonética articulatoria, como un sonido oclusivo bilabial sonoro; el segundo, como un sonido fricativo o aproximante bilabial sonoro. Más allá de esta terminología especializada, lo que interesa aquí es señalar que, por poner un caso, pronunciamos en español la 'b' de "barco" diferente de la de "lobo" (la primera es la oclusiva que representamos como [b] y la segunda es la fricativa [B]). Sin embargo, en términos funcionales, en cuanto a lo que "entendemos", cualquiera de los dos sonidos valen como si fueran lo mismo; es decir, ambos nos remiten al mismo fonema o unidad funcional, a diferencia de /b/ en relación con $/ \mathrm{p} /$, los cuales sí se oponen y sirven para crear significados distintos.

Resulta poco práctico que un sistema de escritura retrate los sonidos, pues estos, además de ser por lo regular más numerosos que los fonemas, dependen de la pronunciación regional, del grupo social, de la edad, del género, del grado de instrucción formal, del individuo y su estado anímico, entre otros factores. Por el contrario, las unidades fonológicas suelen ser más estables y varían poco entre las regiones en las que se utiliza una misma lengua. En este sentido, a veces se ha llegado a afirmar que la ortografía del español es bastante fonológica (representa fonemas), pero no fonética (no representa sonidos), aunque también dicha representación es imperfecta.

En un sistema de escritura como el del español, las letras sirven como una especie de imagen del sistema fonéticofonológico, pero los cambios en la lengua y las inconsistencias que desde el origen se encontraban han llegado a romper con la función representativa de muchas de las grafías. De este modo, únicamente nueve letras y dígrafos (combinación de dos letras) mantienen una correspondencia exclusiva con un solo fonema del español: $a, c h, d, e$, $f, l, o, p$ y $t$; las veintiuna letras o dígrafos restantes no mantienen correspondencias exclusivas, sino que o bien dos o más de ellas representan el mismo fonema (caso de $s, c$ y $z$ en el español de Hispanoamérica, y de $b$ y $v$ en todo el mundo hispanohablante), o una de ellas representa varios fonemas (caso de g, que representa dos fonemas distintos, como en "gato" y "gente"), o una letra representa un conjunto de fonemas (como sucede $\operatorname{con} x$ ) o bien no representa ninguno (como la $h$ ) (cfs. Teschner, 1999; Rabanales, 2000). Son precisamente estas faltas de exclusividad las que provocan los problemas ortográficos en los usuarios.

Ante esta inconsistencia, cabría proponer algunas soluciones. La primera, quizás la que atacaría el problema en sus raíces verdaderas, sería la reforma ortográfica. Básicamente, la ortografía actual del español está cimentada en tres criterios: la etimología (cómo se escribía en latín o en otras lenguas de las que proviene la palabra y que explicaría la pervivencia de, por ejemplo, las letras $h$ y $v$ ), la tradición (criterio aplicado en casos en los que se ha mantenido una grafía como la de "escribir" con $b$ en lugar de la etimológica v) y la representación del sistema fonológico (Rabanales, 2000). Tal mezcla de parámetros provoca no pocas inconsistencias, las cuales se han tratado de resolver mediante reglas ortográficas como las que ya comentamos, sin tomar en consideración que, a fin de cuentas, la "buena" ortografía depende de la memoria visual, a causa de las divergentes grafías para los mismos fonemas.

Existen propuestas serias de reforma ortográfica del español. La más conocida quizás sea la de Andrés Bello y Juan García del Río de 1823 (cfs. Mosterín, 1981; Rabanales, 2000). Una más reciente y elaborada con criterios basados en la ciencia lingüística es la que postula Mosterín (1981) con base en dos premisas: la máxima conservadora de prudencia (no proponer cambios cuando las razones no sean lo suficientemente claras) y la máxima de universalidad (evitar las soluciones idiosincráticas, ad hoc o las tentaciones de originalidad), pues las soluciones deben tener validez para otras lenguas. 
Para Mosterín (1981), la escritura alfabética debe atenerse a un principio fonológico, pero debe complementarse con parámetros semánticos, morfológicos y transdialectales. Por ello mismo, propone la eliminación de la letra $h$ por motivos fonológicos, pero su permanencia en algunos vocablos, como herrar frente a su homófono errar, como una especie de desambiguador gráfico. Empero, el argumento de mostrar, en la grafía, la diferencia semántica entre dos palabras distintas pero con idéntica estructura fonológica resulta, a todas luces, artificioso e innecesario, como el mismo Mosterín lo comenta repetidas veces. Retener reliquias ortográficas bajo el argumento de la desambiguación escrita desmerece cualquier intento de simplificar la ortografía de nuestra lengua, para así hacerla más fácil de aprender y utilizar, cuando la premisa de partida es lograr la correspondencia letra-fonema.

Un intento de solución dentro de los márgenes de la ortografía tal y como es en la actualidad la encontramos en Teschner (1999), quien recurre a dos procedimientos: descubrir las semejanzas ortográficas en grupos de palabras y realizar estadísticas para hallar tendencias de escritura. Como se ha de apreciar, no obstante, la comprensión del método de Teschner requiere un conocimiento básico de nociones de fonología:

Veamos varios ejemplos de estos dos procedimientos. Primero, un grupo grande de semejanzas ortográficas: casi todas las 900 palabras que terminan con los sonidos /smo/ representan el fonema $/ \mathrm{s} / \mathrm{de} / \mathrm{smo} /$ con el grafema "s" y no con el "z", lo cual constituye un grupo grande. (Hay sólo dos de las 900 -diezmo, rediezmo- que se escriben con -zmo en vez de -smo.) Ahora observemos la utilización de estadísticas: por lo menos el 75 por ciento de las palabras que contienen el fonema /j/ lo representan con el dígrafo "ll" en vez del grafema "y". Por lo tanto, estas estadísticas nos pueden ayudar a determinar la ortografía más probable de una palabra que contiene el fonema /j/: en caso de duda, escríbase "ll” (Teschner, 1999, p. 12).

En particular, Teschner se detiene en el análisis de los ocho problemas ortográficos que, a su entender, son los más importantes y frecuentes: /s/ = "c" "s" "z", /k/ = "qu" "c" "k", /g/ = "gu" "g", /x/ = "g" "j", /j/ consonántico = "ll" "y", /j/ aproximante = "y" "i" en un diptongo, /b/ = "b" "v", /r/ = "rr" "r", y el grafema "h" = Ø. De esta forma, se optimizan las reglas y se concentra la atención en aquellas que resultan verdaderamente rentables, en vez de invertir tanto tiempo en la memorización de grandes listados en los cuales muchas de las reglas se aplican a escasísimos casos.

Por ejemplo, para el problema $/ \mathrm{s} /=$ "c" "s" "z", afirma que, en general, se emplea más la letra "s" que las otras dos para representar el fonema /s/ y presenta los cinco grupos en los cuales "s" es la escritura exclusiva o mayoritaria: /-sta/ = ."sta" (unas 800 palabras), /-oso/ = "-oso" (cerca de mil palabras; hay unos 300 ejemplos de “-ozo"), /-smo/ = "-smo" (unas 900 palabras, con dos excepciones), /-sko/ = "-sco" (unas 200 palabras; las formas con "-zco" suelen ser conjugaciones de verbos cuyos infinitivos terminan en -cer), /-sis/ = "-sis" (unos 200 vocablos). El grafema "z" solo predomina en /-aso/ = "-azo", especialmente con el valor de tamaño desproporcionado, golpe o fuerza. La letra "c", por su parte, predomina en dos grupos: /-sio/ = "-cio" y /-sia/ = "-cia” o /-sí-a/ = “-cía” (unas 1000 palabras, frente a 166 términos que se escriben con "-sia" o "-sía").

A partir del análisis de léxico básico escolar, Murillo (2003) también establece nueve problemas ortográficos (reglas rentables) con subdivisiones, con el fin de que sirvan como guía para el planeamiento de la clase de primaria: la acentuación de la sílaba tónica en palabras agudas, graves y esdrújulas; la letra $b$ (los verbos 'deber, beber, saber, haber'; las terminaciones en -ba del imperfecto de indicativo); la letra $v$ (los pretéritos perfecto de indicativo $\mathrm{e}$ imperfecto de subjuntivo de 'estar, andar, tener' y sus compuestos); los verbos 'llevar, venir, volver, ver' y 'vivir'; las palabras con la secuencia gráfica nv; la letra $c$ (terminaciones -cción y -ción; las palabras 'entonces, cerca, necesario, hacia, cierto'); la letra 
$s$ (las palabras 'ser, así, casi'); la letra $z$ (-zc de la primera persona singular del presente de indicativo y todo el presente de subjuntivo de los verbos terminados en -acer, -ecer, -ocer y -ucir; -z final de las palabras con plural en -ces); el dígrafo $r r$; las secuencias mp y mb; el paradigma de los verbos 'estar, haber, hacer, caer, ir, ser'.

No obstante, la cuestión de la enseñanza-aprendizaje de la escritura convencional puede presentarse desde otro enfoque. Matteoda y Vázquez (1997) defienden la existencia de tres dimensiones al respecto: la lingüística, la cognitiva y la pedagógica.

En cuanto al componente lingüístico, Matteoda y Vázquez redefinen la relación entre oralidad y escritura con respecto al carácter ancilar de la segunda para con la primera; así, se reconceptualiza la representación ortográfica de la lengua desde una posición fonográfica a una grafemática, y de una reflexión fonológica a una semántica. Es decir, se deja la concepción fonocentrista de la escritura como transcripción del sistema fonológico y, con ello, se abandonan los criterios de correspondencia fonema-letra, con el consiguiente abandono también de las críticas acerca de la consideración como superfluos de los grafemas que, al estilo de la $h$, no representan ningún fonema.

Esta nueva perspectiva de abordar el problema parte de la consideración de los sistemas de escritura como pertenecientes a la modalidad escrita del discurso, la cual no se piensa más como representación de la modalidad oral, sino como un sistema relacionado pero, al mismo tiempo, independiente, con sus propios recursos y estructuración. En este enfoque, los sistemas de escritura se valoran desde una óptica diamentralmente opuesta al canon de la lingüística estructural: el registro escrito no se concibe como mera transcripción del oral, ni se piensa este último como el verdadero y el único digno de estudio; la escritura deja de ser un fenómeno parasitario o ancilar de la oralidad, para llegar a caracterizarse como una variedad de codificación lingüística emparentada con el registro oral, pero al mismo tiempo con su propia especificidad (cfs. Sampson, 1997).

De este modo, la ortografía se caracteriza como una grafemática, una representación escrita de estructuras lingüísticas. Por consiguiente, la función de la ortografía es representar unidades semánticas o funcionales (por ejemplo, la separación de las palabras) y paradigmas léxicos y gramaticales a partir de constantes ortográficas, como en la raíz clav de 'clavo', 'clavar', o la representación del morfema -ba de imperfecto de indicativo. También, como consecuencia, las constantes ortográficas ayudan a representar la pertenencia de un rubro a un paradigma distinto, como en bidente y vidente.

Esta dimensión lingüística se relaciona estrechamente con la dimensión psicológica, pues las autoras reseñan los resultados de estudios en los cuales se ha llegado a la conclusión de que los individuos escolarizados pasan de una reflexión centrada en la correspondencia grafía-fonología a una concentrada en estructuras morfosintácticas, léxicas y textuales.

Por su parte, la dimensión pedagógica ha fallado en el tanto se ha centrado en la enseñanza de la ortografía como un contenido por sí mismo, practicado por lo común en ejercicios de complete de espacios y, a lo sumo, concentrado en el nivel de la palabra, con lo cual se ha desvinculado la materia de la producción textual, ámbito en el que, a fin de cuentas, encuentra su razón de ser.

En este aspecto, cabe señalar la coincidencia con lo que ya hemos argumentado para los otros aspectos relativos a la didáctica de la expresión escrita en Costa Rica: la redacción y la ortografía no se han concebido como lo que son: producción de textos; sino como análisis gramatical, transcripción de palabras, seguimiento de reglas prescriptivas (cfs. Sánchez, 2004a). Así, la ortografía, al igual que la puntuación, se ha visto despojada de cualquier valoración 
por parte de los aprendices. Pareciera ser un requisito más de la escolarización descontextualizada y sin sentido de la que son víctimas, un aspecto más por memorizar, sin que se le halle lógica o beneficio.

Por ello, Matteoda y Vázquez (1997) recomiendan un cambio didáctico en el tratamiento de la ortografía: abandonar las reglas ortográficas descontextualizadas y fonodependientes e implementar ejercicios de justificación de la ortografía en situaciones de producción textual.

Este cambio de perspectiva también nos ayudaría a frenar el juicio sobre las emisiones orales a partir de la convención ortográfica, el cual consiste, tal como lo denominó Rosenblat (1970), en el "fetichismo de la letra": juzgar lo oral como incorrecto a partir de lo escrito; es decir, evaluar la correcta pronunciación a partir de la escritura, como suelen hacer los autores de los manuales para el aprendizaje de la expresión escrita en sus famosas listas de vicios del lenguaje.

El traslado de la concepción fonográfica a la grafológica exige, además, una revisión del concepto de grafema. Aunque en este trabajo hemos consignado poco este término, en toda la bibliografía consultada se aprecia una equiparación absoluta entre letra y grafema. Pellat (1996), al examinar las diversas definiciones de grafema, logra inventariar al menos cuatro acepciones distintas: el grafema se equipara a la letra, como término técnico para designar la unidad mínima del registro escrito; el grafema es la representación del fonema, con el cual establece una relación de dependencia unilateral; el grafema, visto en su especificidad, se concibe como unidad distintiva mínima del sistema gráfico, independiente del sistema fonológico; y el grafema es una unidad polivalente, pues su función depende del sistema de escritura específico. Esta última noción reconoce un carácter mixto de la unidad, una doble naturaleza: fonográfica cuando se lee en voz alta y semagráfica, cuando se realiza lectura visual y se rescatan los significados, más que su correspondencia con unidades de pronunciación.

Como se observa, las primeras dos definiciones son las que han manejado los autores costarricenses que se han ocupado del tema de los problemas ortográficos en la población estudiantil: o se homologa grafema con letra o se insiste en el grafema como representación del fonema, a partir de lo cual se estudian las faltas de correspondencia y la desactualización del sistema ortográfico.

Por el contrario, las dos últimas definiciones se acercan al planteamiento grafológico de la ortografía de Matteoda y Vázquez (1997): los grafemas cumplen una función semántico-gramatical, al distinguir palabras homófonas y al revelar paradigmas léxico-morfológicos. Es decir, se aboga aquí por la separación y consideración de la autonomía de las dos grandes vías de materialización del discurso: oral y escrita.

En todo caso, consideramos que, sea que se adhiera uno a la concepción grafológica de la ortografía o que se siga aludiendo a la cuestión fonográfica, la memoria visual continúa vislumbrándose como de fundamental importancia para el aprendizaje de la escritura convencional de los signos gráficos.

En su libro sobre la memoria, Schacter (1999) expone los fundamentos de lo que, en psicología cognitiva, se denomina proceso de codificación, un procedimiento a partir del cual los seres humanos transformamos en recuerdo lo que oímos, vemos, sentimos o pensamos, a partir de prestar atención a los acontecimientos o datos. Por lo regular, acudimos a nuestra memoria de trabajo para guardar información por muy poco tiempo, como un número de teléfono que nos dictan, lo cual lleva a una codificación superficial y a un recuerdo pasajero. Para que algo se fije en la memoria, debe codificarse con mayor profundidad o conciencia, mediante una asociación significativa con respecto a lo que ya se encuentra almacenado en la memoria, lo cual se conoce con el tecnicismo de profundidad del procesamiento. 
Esta codificación elaborada permite integrar a los conocimientos existentes la información nueva y provoca un recuerdo duradero, pero para que tenga efecto debe reflexionarse sobre la información que se desea recordar y se debe conectar con el conocimiento previo, de forma tal que la codificación incidirá en la cantidad y la calidad de lo recordado. A este respecto, una cita de Schacter puede resultar reveladora para el tema que nos compete:

(...) que el recuerdo manifiesto dependa de la elaboración también presenta un inconveniente: si la codificación no es elaborada, nos quedaremos con unos recuerdos empobrecidos. Diversos experimentos han demostrado que, sorprendentemente, apenas recordamos lo que hay en el anverso y el reverso de las monedas, a pesar de verlas y utilizarlas constantemente. Es probable, no obstante, que codifiquemos los rasgos de las monedas de forma bastante superficial, pues para emplearlas en la vida cotidiana basta con reconocer su forma y su color. El proceso de codificación puede detenerse una vez elaborada la información necesaria; no hay ninguna necesidad de efectuar un análisis minucioso de las monedas (...). Si actuamos como guiados por el piloto automático la mayor parte del tiempo y no reflexionamos acerca de nuestro entorno y nuestras experiencias, podemos pagar el precio de retener sólo bosquejos de recuerdos de los lugares donde hemos estado y de las cosas que hemos hecho (Schacter, 1999, p. 72-73).

Así las cosas, es probable que, para la correcta representación escrita de una palabra (sea cual sea la postura que se asuma con respecto a la ortografía), se requiera de poner en funcionamiento los mecanismos de la codificación elaborada. Si el estudiantado no es capaz de apreciar el valor de la representación escrita convencional, si no puede integrar la regla ortográfica o la constante gráfica del paradigma léxicogramatical respectivo a su conocimiento previo, si el aprendizaje de la escritura no se logra concebir como aprendizaje significativo y el recuerdo ortográfico (el cual lleva, sin duda, al sentido ortográfico del que hablaba Vincenzi) no se realiza a profundidad a partir de la reflexión consciente sobre la manera en que se escribe y las relaciones semánticas que se despliegan en el texto, entonces la cacografía aparecerá recurrentemente -quizás hasta el grado de fosilizarse- y ninguna acción didáctica podrá evitarlo.

\section{Conclusiones}

En una cafetería universitaria nos encontramos no hace mucho tiempo esta maravilla lingüística: "Los Precios Nó Incluyen El Desechable”, referida a que los valores consignados de los platos de ese día no incluían el precio de los recipientes de la comida para llevar. Decimos que se trata de una maravilla, porque muestra a la perfección el valor que un hablante les puede asignar a los signos ortográficos; en este caso particular, a la tilde: el 'Nó' del texto es un 'no' contundente, enfático, sin posibilidades de negociación o queja, y este valor se lo da la tilde. En otras palabras, en este ejemplo la tilde cumple una función pragmática, a pesar de la violación de la regla normativa sobre el uso de este signo gráfico. Si quienes escriben pudieran disponer de los grafemas para marcar este tipo de información, entonces la ortografía sí cumpliría una función textual y sería fácil de comprender su valor.

Sin embargo, en nuestra lengua la ortografía no cumple una función discursiva, aunque -si se ha de seguir a Matteoda y Vázquez (1997) - sí desempeña una función semántica y paradigmática, lo cual debe ser claro para quien la aprende, con la finalidad de que le encuentre un valor y un propósito al aprendizaje de la escritura convencional de la lengua, mientras no se produzca una reforma ortográfica que simplifique el sistema y lo actualice en términos fonológicos. Ya tratamos de mostrar que la analogía actúa también como factor causante de las cacografías, por lo cual la tesis del reconocimiento de paradigmas representados por constantes gráficas adquiere mayor validez.

Lejos de proponer un programa o al menos una técnica para la didáctica de la 
ortografía, queremos insistir en varios de los principales puntos esgrimidos:

Debe hacerse evidente y practicarse el valor grafemático de la ortografía, en cuanto representación de constantes paradigmáticas y desambiguación de rubros léxicos homófonos.

Debe enfatizarse la práctica de la ortografía al mismo nivel que la de los demás componentes involucrados en la producción escrita: el texto, la unidad comunicativa real y básica, en la que los elementos lingüísticos se actualizan, se relacionan y adquieren su verdadero sentido.

Debe promoverse la comprensión en el estudiantado de que el registro escrito es independiente del oral, aunque ambos sean manifestaciones del mismo sistema lingüístico básico. En este sentido, debe enfatizarse que no se escribe como se habla, no porque se hable mal ni mucho menos, sino simplemente porque son registros distintos, con recursos y estrategias también diferentes, que responden a valoraciones sociales específicas para cada uno $\mathrm{y}$, sobre todo, a requerimientos de estructura por las condiciones de producción, recepción y decodificación particulares.

Debe revisarse la enseñanza a partir de reglas, pues la mayoría de estas son sumamente deficientes, poco prácticas y escasamente rentables. Si se ha de recurrir a una regla ortográfica, debe procurarse que esta responda a los criterios de formulación expuestos, que sea aplicable a muchos casos y que resulte fácil de comprender y poner en ejecución. Además, debe ejercitarse en la producción textual y motivarse al alumnado a justificar sus "elecciones". En todo caso, como lo expresó Zamora desde 1930, la regla debe verse como simple guía y no como precepto.
Debe realizarse el estudio de la ortografía a partir del vocabulario conocido y útil para la niñez y la juventud, el que comprenden y pueden emplear en sus escritos, como procedimiento fundamental, tal y como lo expusieron Zamora en 1930 y Vincenzi en 1939. Para este efecto, en el caso de los escolares, el aporte de Murillo (2003) no se puede ignorar, por su relevancia, rigurosidad y posibilidades de aplicación.

Debe desterrarse, por falsa y prejuiciosa, la idea de que las faltas ortográficas revelan un nivel inferior de cultura, una insuficiencia degradante o un problema de higiene lingüística, como lo afirman los autores de muchos manuales de ortografía. Una cacografía es el resultado de muchos factores, entre ellos los problemas en la didáctica con la que se ha abordado la enseñanza. Si se quiere que el estudiantado aprecie el valor de escribir convencionalmente, entonces los argumentos deben ser otros, sin culpar a quienes escriben por las inconsistencias del sistema ortográfico actual y sin recurrir a falacias.

\section{Notas}

1. Se trata de la segunda edición. Ignoramos la fecha de la anterior.

2. Lathrop, T. (1995, p. 219) señala que, en la Edad Media, las grafías $b$ y $v$, en posición intervocálica, solían aparecer con frecuencia y sin confundirse, lo cual implicaría la posibilidad de que existiera un sonido oclusivo frente a uno fricativo. Sin embargo, aclara también que es discutible la naturaleza exacta del segmento fricativo, pues no se sabe si era labiodental o bilabial.

3. Se trata de Selección de palabras para ortografía de Lilia González y Manuel Clemente Quesada, obra publicada en 1930 y en la que los autores sistematizan, a partir de textos redactados por estudiantes de primaria, listados de rubros léxicos que se deben dominar por nivel. Vincenzi explicita la autoría del estudio, pero no la fuente. La 
referencia completa se encuentra en Rojas y Aguilar (2006).

Aunque, tal como se apuntó en Sánchez (2004b), estas autoras proponen un método inductivo (observar la escritura de las palabras en fragmentos de textos y elaborar listas según la letra con la que aparezcan) y de búsqueda por parte del discente de la regla que se aplicaría para cada caso.

Mención aparte merece la confusión entre memoria fotográfica (o, técnicamente, memoria eidética: aquella capacidad de algunos individuos de retener una imagen completa y reconstruir sus detalles con precisión a pesar de solo haberla visto durante poco tiempo) y memoria visual (aquella que codifica el recuerdo por medio de un estímulo visual). Si solamente quienes han tenido la suerte de desarrollar la habilidad conocida como memoria fotográfica pudieran servirse de ella para escribir con ortografía, la mayoría de nosotros estaríamos condenados a la exclusión.

Y en el caso de BR y BL, sería más práctico decir que no existen las combinaciones gráficas VR y VL.

7. Utilizo, para la representación de los fonemas, los símbolos del Alfabeto Fonético Internacional. Para todo aquel que no esté familiarizado con el asunto, lo único que interesa aquí es mostrar cómo a una unidad fonológica (representada entre barras, sin importar realmente, para los efectos de esta exposición, el símbolo que se utilice) corresponden dos o más letras.

8. La estupefacción de Chavarría se debe a que la letra $\mathrm{h}$ no representa ningún fonema -ni sonido- en el español moderno.

9.

Sin duda, y aunque Bruck es omiso al respecto, tales errores tan usuales de la población costarricense tendrían que ver con letras como $s, c$ y $z$, las cuales en gran parte del español peninsular sí representan dos fonemas distintos.

\section{Referencias bibliográficas}

Bolaños，B. (1996). Comunicación escrita. San José: Editorial Universidad Estatal a Distancia.
Bruck, A. (1942). Método Psicológico de Ortografía Castellana. San José, Costa Rica: Soley y Valverde.

Chavarría, Ó. (1988). La ortografía en perspectiva. Cartago, Costa Rica: Editorial Tecnológica de Costa Rica.

Fernández, M. (2001). Gramática, ortografía y redacción para bachillerato. San José, Costa Rica: Editorial Fernández-Arce.

Gámez, M. Ortografía. (1928). San José: Librería e Imprenta Universal.

Garita, F. y Quesada, M. (1988). Prácticas de ortografía. San José, Costa Rica: Editorial Nueva Década.

Lathrop, T. (1995). Curso de gramática histórica española. Barcelona: Ariel.

Matteoda, M. C. y Vázquez de Aprá, A. (1997). Acerca de la ortografía y su aprendizaje en el contexto escolar. En: Textos de didáctica de la lengua y la literatura, 14, 79-87, Barcelona: GRAO.

Mosterín, J. (1981). La ortografía fonémica del español. Madrid: Alianza Editorial.

Moya, J. (1981). Ortografía para educación comercial. San José, Costa Rica: Editorial Fernández-Arce.

Murillo, M. (2003). Estudio sobre el lenguaje de los escolares costarricenses: El léxico básico. La ortografía y sus características. Tesis doctoral, Universidad de Extremadura, Cáceres.

Pacheco, V. y Álvarez, M. A. (1997). Comunicación escrita y oral. San José, Costa Rica: CQ Impresos, S. A. 
Pazos, E. (1990). Acentuación y ortografía. San José, Costa Rica: Euroamericana de Ediciones.

Pellat, Jean-Christophe. (1996). Inventario crítico de las definiciones del grafema. En N. Catach (Comp.). Hacia una teoría de la lengua escrita (pp. 171-194). Barcelona: Gedisa.

Pérez, F. (1991). ¿Es posible enseñar la ortografía acentual? Educación Revista de la Universidad de Costa Rica, 15 (2), 67-74.

Porras, Á. (1972). Ortografía textual. San José, C. R.: Editorial Fernández Arce.

Rabanales, A. (2000). En torno a la reforma ortográfica. En A. Valencia y L. Piña (eds.), Actasdel CongresoInternacional "El español culto en el mundo hispánico" (pp. 57-65). Santiago de Chile: ALFAL, Universidad Bolivariana.

Rodino, A. M., y Ross, R. (1985). Problemas de Expresión Escrita del Estudiante Universitario Costarricense. Un estudio de lingüística aplicada. San José: Editorial de la Universidad Estatal a Distancia.

Rojas, M., García, N. y Fajardo, D. (1985). Diagnóstico evaluativo de la enseñanza del español en la Educación General Básicay Educación Diversificada: rendimiento académico. (Informe final). San Pedro, Costa Rica: Instituto de Investigación para el Mejoramiento de la Educación Costarricense.

Rojas, M. y Aguilar, Ó. (2006). ¿Práctica de palabras o de ideas? Panorama histórico de la enseñanza del léxico en Costa Rica. Educación Revista de la Universsidad de Costa Rica 30(1), 103-126.
Rosenblat,Á. (1970). El castellano de España y el castellano de América: unidad y diferenciación. Madrid: Taurus.

Sampson, G. (1997). Sistemas de escritura. Barcelona: Gedisa.

Sánchez, C. (2004a). Historiografía de la enseñanza de la redacción en Costa Rica: los libros de texto. Revista de Filología y Lingüística, XXX(1), 219-246.

Sánchez, C. (2004b). La puntuación y las unidades textuales: Una perspectiva discursiva para el estudio de los problemas de su uso y para su enseñanza. Educación Revista de la Universidad de Costa Rica, 28(2), 233-254.

Sánchez, Carlos. (2005). Los problemas de redacción de los estudiantes costarricenses: Una propuesta de revisión desde la lingüística del texto. Revista de Filología y Lingüistica, XXXI(1), 267-295.

Schacter, D. L. (1999). En busca de la memoria. El cerebro, la mente y el pasado. Barcelona: Ediciones B.

Sotela, R. (1929). Complemento gramatical de los programas de castellano. San José: Librería e imprenta Alsina.

Soto, C. L., Víquez, B. y Ramírez, L. F. (1988). Texto programado de ortografía española. San José, C. R.: Editorial Nueva Década.

Swan, M. (1994). Design Criteria for Pedagogic Language Rules [Criterios para el diseño de reglas lingüísticas pedagóticas]. En M. Bygate, A. Tonkyn y E. Williams (Eds.), Grammar and the Language teacher [La gramática y el professor de lengua] (pp. 45-55). Nueva York: Prentice Hall. 
Teschner, R. (1999). Camino oral. Fonética, fonología y práctica de los sonidos del español. Boston: McGraw-Hill.

Varela, M. y Sandino, W. (1993). Redacción y ortografía. Una opción para todos. Heredia, Costa Rica: Ediciones Marwal.
Vincenzi, M. (1939). La enseñanza de la ortografía. San José: Soley y Valverde.

Zamora, H. (1930). Apuntes sobre enseñanza de la ortografía. San José: Imprenta Lehmann.

Zamora, H. (1942). Educación de la Lengua Materna. San José: Imprenta La Tribuna. 